\title{
Antigens recognised by the human immune response to infection with Leptospira interrogans serovar hardjo
}

\author{
A. J. CHAPMAN, B. ADLER and S. FAINE \\ Department of Microbiology, Monash University, Clayton, 3168, Victoria, Australia
}

\begin{abstract}
Summary. Serum samples from patients infected with Leptospira interrogans serovar hardjo were tested by the microscopic agglutination test (MAT), enzyme immunoassay (EIA) and immunoblotting. There was no apparent correlation between MAT titre and EIA optical density (OD) for individual serum samples, but sequential serum samples produced similar profiles in both tests during the course of an infection. Immunoblotting of hardjo sonicate with patients' sera revealed reactions with a number of bands, in the mol. wt $\left(10^{3}\right)$ range $14 \cdot 4-95$. However, all serum samples reacted with the major $28 \times 10^{3}$-mol. wt sub-unit of hardjo lipopolysaccharide (LPS) and most reacted with a $(34.5-35) \times 10^{3}$-mol. wt flagella doublet. Examination of sequential serum samples obtained over a period of about 3 months after infection revealed little change in the antigens detected after the second to third week of infection. Absorption of patients' sera with whole viable leptospires revealed that antibodies to several exposed antigens, including LPS, were produced. Sera which reacted with hardjo flagella also reacted with bands of similar mol. wts in preparations from other serovars.
\end{abstract}

\section{Introduction}

Leptospirosis is an acute febrile illness, the severity of which varies from mild to rapidly fatal. The causative bacterium Leptospira interrogans is classified serologically into more than 180 serovars (Faine, 1982). In Australia and New Zealand, leptospirosis is most frequently caused by serovar hardjo or serovar pomona (Adler and Faine, 1980; Blackmore and Schollum, 1982). Infections with serovar hardjo are acquired mainly from cattle and are usually observed in dairy farmers, whereas serovar pomona infections occur in other occupational groups associated with animals, such as slaughtermen and meat inspectors (Mackintosh et al., 1980; Blackmore and Schollum, 1982; Faine, 1982; Swart et al., 1983).

Leptospirosis may remain undiagnosed because the symptoms are non-specific (Kaufmann, 1976) or may be confused with other illnesses, especially in the early stages of infection (Faine, 1982). Therefore, laboratory tests are frequently necessary to confirm the diagnosis. The microscopic agglutination test (MAT) for the detection of specific antileptospiral antibodies is currently the most commonly used diagnostic test (Faine, 1982), despite the limitations imposed by the need to

Received 13 Feb. 1987; accepted 17 July 1987. maintain cultures of several leptospiral serovars and the subjectivity involved in reading and interpreting the results.

Enzyme-linked immunosorbent assays (ELISA or EIA) were developed in an attempt to circumvent these problems. Adler et al. (1980) used ultrasonicated leptospires as the antigen, and found that the predominant class of reacting antibody in human sera was IgM. Terpstra et al. (1980) used a heated culture supernate as the antigen and found that their test was genus-specific, but they did not classify the reacting antibody. Milner et al. (1985) found that an IgM ELISA test with a sonicated antigen preparation was sensitive and reproducible for the detection of human anti-hardjo antibodies. They agreed with Adler et al. (1980) that the ELISA test was capable of detecting antigens in addition to those detected by the MAT. However, the nature of the antigens detected by these methods is unknown. Indeed, little is known about the identity of the antigens involved in the response to leptospiral infections.

Nunes-Edwards et al. (1985) investigated the protein antigens recognised by IgG antibodies in hyperimmune rabbit anti-hardjo sera. Most antigens detected by these sera had mol. wts between $30 \times 10^{3}$ and $66.5 \times 10^{3}$ and were present in the outer envelope. It is difficult to relate this study to natural human infections because the reactivities 
of IgG antibodies were investigated, whereas IgM is the predominant antibody class in man (Adler $e t$ al., 1980). Moreover, only protein antigens were investigated and lipid and carbohydrate components of the outer envelope (Auran et al., 1975; Zeigler and VanEseltine, 1975) may also be important antigens.

More information about the identity and nature of the antigens recognised during naturally acquired infections is needed to elucidate those antigens with significance for immunity and diagnosis. We have investigated by immunoblotting the antigens involved in the human antibody response to natural infections with $L$. interrogans serovar hardjo, and the time-course of the IgM and IgG responses to various antigens during different stages of infection.

\section{Materials and methods}

\section{Leptospires}

Three isolates of $L$. interrogans serovar hardjo were used. The reference strain Hardjoprajitno (designated L13) was isolated in 1938 from a Sumatran rubberplantation worker (Wolff, 1953). Strain L171 was a bovine isolate obtained from R. Marshall, New Zealand, and strain L187 was isolated from a human placenta (Faine et al., 1984) in Australia. Other serovars were obtained from previously described sources (Adler and Faine, $1983 a$ ). Leptospires were grown at $30^{\circ} \mathrm{C}$ in Tweenalbumin EMJH medium with added pyruvate (Johnson et al., 1973) and washed three times with phosphate buffered saline, $p \mathrm{H} 7 \cdot 2$ (PBS), to remove adherent bovine serum albumin (BSA).

\section{Human serum samples}

Sequential serum samples obtained from patients with culturally proven leptospirosis caused by serovar hardjo (patients 1-3) were provided by the National Health Institute, Wellington, New Zealand. Further individual serum samples from Australian patients (patients A-E), reactive with serovar hardjo by MAT, were selected from specimens submitted to this laboratory for leptospirosis serology. Human sera were absorbed with whole, viable leptospires as previously described (Adler and Faine, 1978).

\section{Serological tests}

The microscopic agglutination test (MAT) was performed as described by Turner (1968), with Cooke microtitration equipment (Cooke Engineering Co., Alexandria, VA, USA) used to prepare serum dilutions. Enzyme immunoassay (EIA) with ultrasonicated leptospiral antigens was based on the procedure described by Adler et al. (1980) with peroxidase-conjugated rabbit anti-human $\mu$-chain $(\operatorname{IgM})$ and $\gamma$-chain $(\operatorname{IgG})$ specific immunoglobulins (DAKO Immunoglobulins a/s, Copen- hagen). All sonicated leptospires were suspended in PBS. The optical density in each well was measured at $488 \mathrm{~nm}$ by a MicroELISA reader (Dynatech Laboratories, Alexandria, VA, USA).

\section{Monoclonal antibodies}

Monoclonal antibodies MUM/F1-1 (IgG1) and MUM/ F1-4 (IgM) were produced from BALB/c mice immunised with $L$. interrogans serovar hardjo (L13) as previously described (Farrelly et al., 1987).

\section{Preparation of leptospiral antigens}

Sonicated leptospiral antigen preparations were produced as previously described (Adler et al., 1980), except that all sonicates were suspended in PBS. The protein content of leptospiral suspensions was determined by the method of Bradford (1976) with BSA as the standard.

Lipopolysaccharide (LPS) was extracted from $L$. interrogans serovar hardjo (L187) by the hot phenol-water method of Westphal and Jann (1965) as previously described (Vinh et al., 1986a).

Flagella were prepared according to the method of Chang and Faine (1970), followed by further purification by caesium chloride density gradient centrifugation, in which flagella were concentrated at a buoyant density of 1.27 (Adler and Faine, 1979).

\section{Gel electrophoresis and immunoblotting}

Samples standardised for protein content were subjected to sodium dodecyl sulphate polyacrylamide gel electrophoresis (SDS-PAGE) on $1.5 \mathrm{~mm}, 10 \%$ gels, with the discontinuous buffer system of Laemmli (1970). After electrophoresis, gels were either stained with Coomassie Brilliant Blue (BDH Chemicals, Kilsyth, Australia) $0.25 \%$ in water: isopropanol: acetic acid at a ratio of $68: 25: 7(\mathrm{v} / \mathrm{v})$, or transblotted on to nitrocellulose (pore size $0.45 \mu \mathrm{m}$; Schleicher and Schuell, Dassel, W. Germany) in a Bio-Rad Trans-Blot cell at 60 volts for $3 \mathrm{~h}$ with the buffer of Towbin et al. (1979) diluted 1 in 2 . The nitrocellulose was then stained with Indian ink (Hancock and Tsang, 1983), or immunostained with human serum. Blots to be immunostained were blocked with skimmed milk 5\% (Johnson et al., 1984) and Tween $200.05 \%$ (Sigma, St Louis, USA) (Batteiger et al., 1982) in Tris-

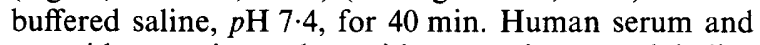
peroxidase-conjugated anti-human immunoglobulins (DAKO) were diluted, 1 in 100 and 1 in 200 respectively, in the blocking buffer and consecutively incubated with the blots for $2 \mathrm{~h}$ at $37^{\circ} \mathrm{C}$. Blots were washed with four 10-min changes of blocking buffer after each incubation and developed with 4-chloro-1-naphthol (Merck, Darmstadt, W. Germany) (Hawkes et al., 1982).

Molecular weights were determined by comparison with mol.-wt markers obtained from either BIO-RAD (Richmond, CA, USA) or Pharmacia AB (Uppsala, Sweden). 


\section{Results}

\section{SDS-PAGE profiles of three isolates of serovar hardjo}

A complex pattern of protein bands with mol. wts ranging from $<20.1 \times 10^{3}$ to $>94 \times 10^{3}$ was observed for each of three serovar hardjo isolates (fig. 1). Many proteins were shared, but there were some differences between the local isolates L171 and L187, and the type strain Hardjoprajitno (L13).

\section{Antibodies in sera, measured by MAT, EIA and immunoblotting}

Individual serum samples that reacted with serovar hardjo by MAT were also tested against serovar hardjo by EIA (table) and by immunoblotting (fig. 2). There was no apparent relationship between MAT titre and EIA optical density (OD) for either $\operatorname{IgM}$ or $\mathrm{IgG}$ antibodies. EIA revealed

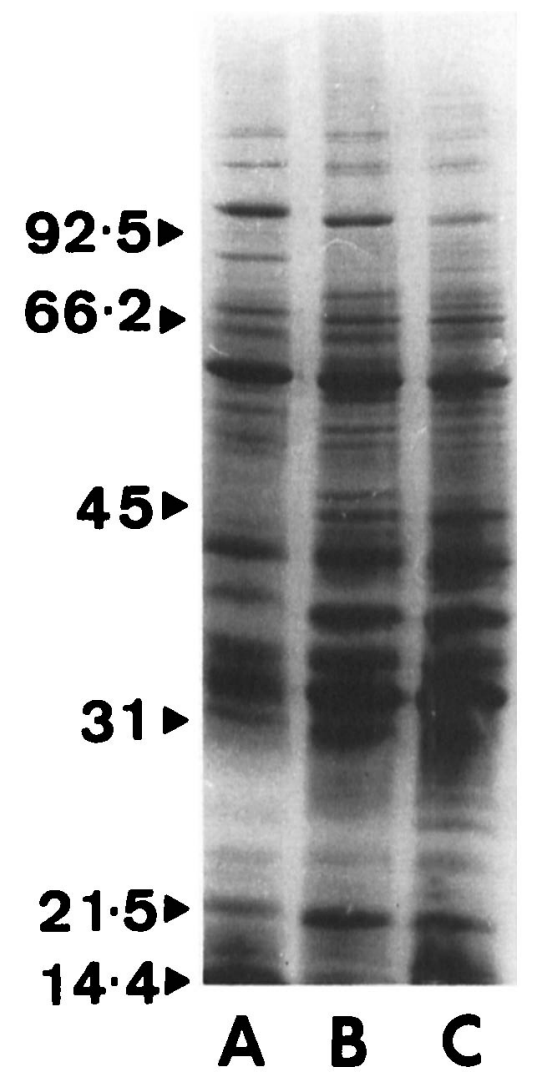

Fig. 1. SDS-PAGE profiles of three strains of $L$. interrogans serovar hardjo stained with Coomassie blue. Lane A strain Hardjoprajitno (L13); lane B, strain L171 ; lane C, strain L187. Numbers on the left indicate mol. wts $\left(10^{3}\right)$ of the standard proteins used.
Table. The presence in human sera of antibodies reacting with L. interrogans serovar hardjo (strain L171) as judged by MAT and EIA

\begin{tabular}{crrr}
\hline & & \multicolumn{2}{c}{ EIA OD $(488 \mathrm{~nm})^{*}$} \\
\cline { 3 - 4 } Patient & MAT titre & IgM & IgG \\
\hline A & 2560 & $0 \cdot 55$ & $0 \cdot 10$ \\
B & 20480 & $0 \cdot 38$ & $0 \cdot 13$ \\
C & 2560 & 0.49 & $0 \cdot 25$ \\
D & 2560 & $1 \cdot 74$ & $0 \cdot 13$ \\
E & 40960 & $0 \cdot 71$ & 0.39 \\
\hline
\end{tabular}

*Adjusted for background.

specific IgM and IgG in all samples although the OD levels for specific IgM were always higher. Individual serum samples from patients $\mathrm{A}-\mathrm{E}$ reacted with bands in the mol.-wt $\left(10^{3}\right)$ range $14 \cdot 4$ 94 when immunoblotted with sonicated hardjo (strain L171) and IgM and IgG specific secondary antibodies (fig. 2). All sera contained IgM antibodies that reacted with a curved band of mol. wt $c$. $28 \times 10^{3}$ to which most samples also contained IgG antibodies. Some samples also contained IgM and IgG antibodies or both, which reacted with a doublet of mol. wt $c$. $(34 \cdot 5-35) \times 10^{3}$. However, a band of mol. wt c. $65 \times 10^{3}$ reacted only with $\mathrm{IgG}$ antibodies.

\section{Identification of some major antigens}

Murine monoclonal antibodies reacting with serovar hardjo lipopolysaccharide (LPS), designated MUM/F1-1 and MUM/F1-4 (Farrelly et al., 1987), were tested by immunoblotting against hardjo sonicate (fig. 3) and found to react with a curved band of mol. wt $28 \times 10^{3}$. Immunoblotting of a purified hardjo LPS preparation with these anti-LPS monoclonal antibodies and human antihardjo serum (fig. 3 ) revealed that there were three major bands, of mol. wts $\left(10^{3}\right) c .15,23$ and 28 , in the LPS preparations. One epitope was present on all three major components, whereas another epitope was present on the mol. wt $28 \times 10^{3}$ component alone. Immunoblotting of a hardjo flagella preparation with human anti-hardjo sera (fig. 3) showed that both IgM and IgG antibodies reacted with a doublet of mol. wt $(34 \cdot 5-35) \times 10^{3}$. Occasional reactions were also noted with bands of mol. wts $\left(10^{3}\right) c .15$ and 30 .

\section{Analysis of antibodies at different stages of infection \\ Serial sets of sera, from three patients whose leptospiral infection with serovar hardjo were}




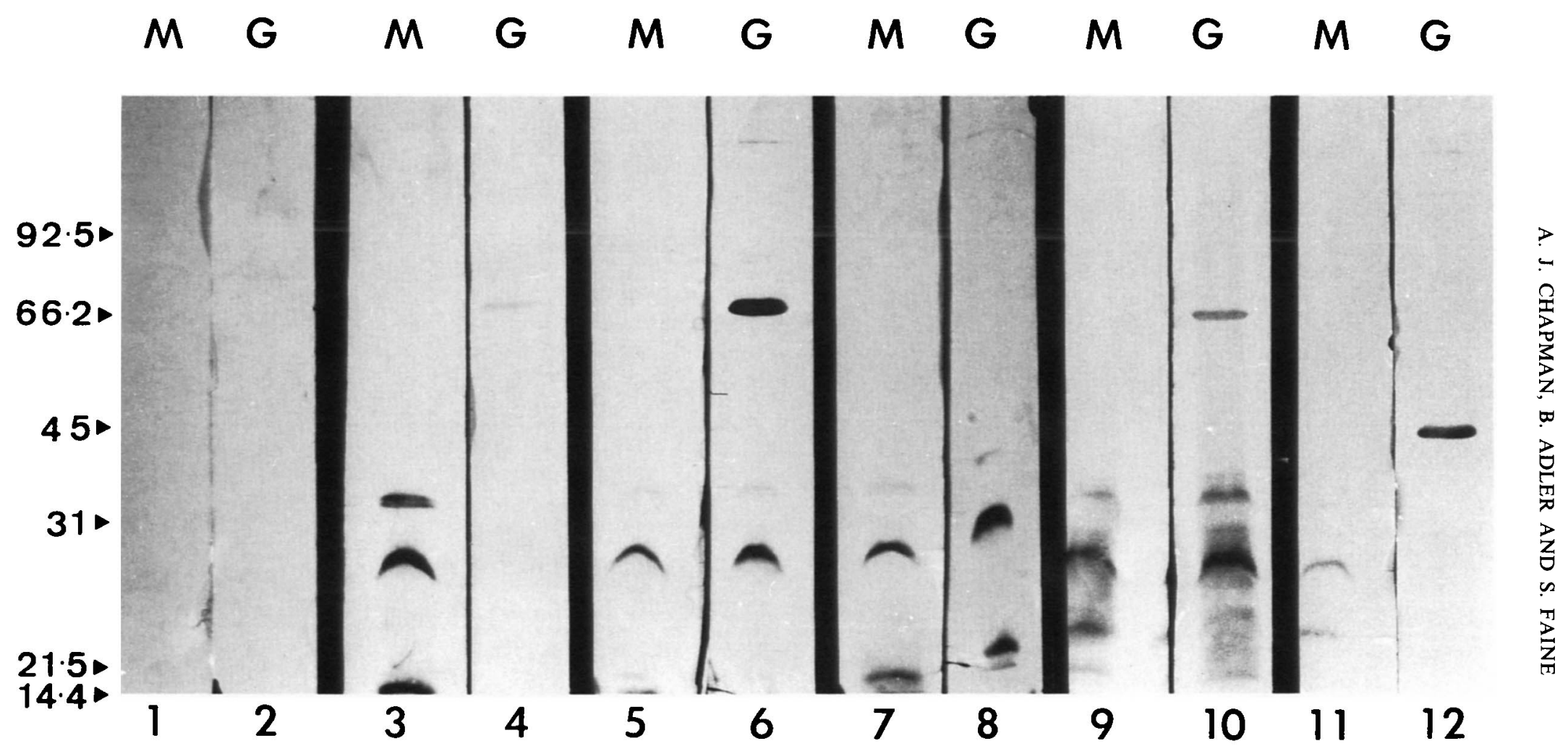

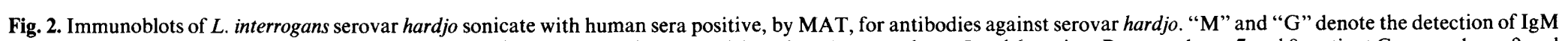

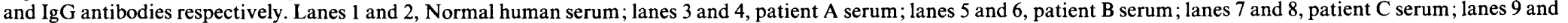
10 , patient D serum; lanes 11 and 12, patient $E$ serum. Numbers on the left indicate mol. wts $\left(10^{3}\right)$ of the standard proteins used. 


\section{$M \quad G \quad M \quad G \quad M \quad G \quad M \quad G \quad M$}

G

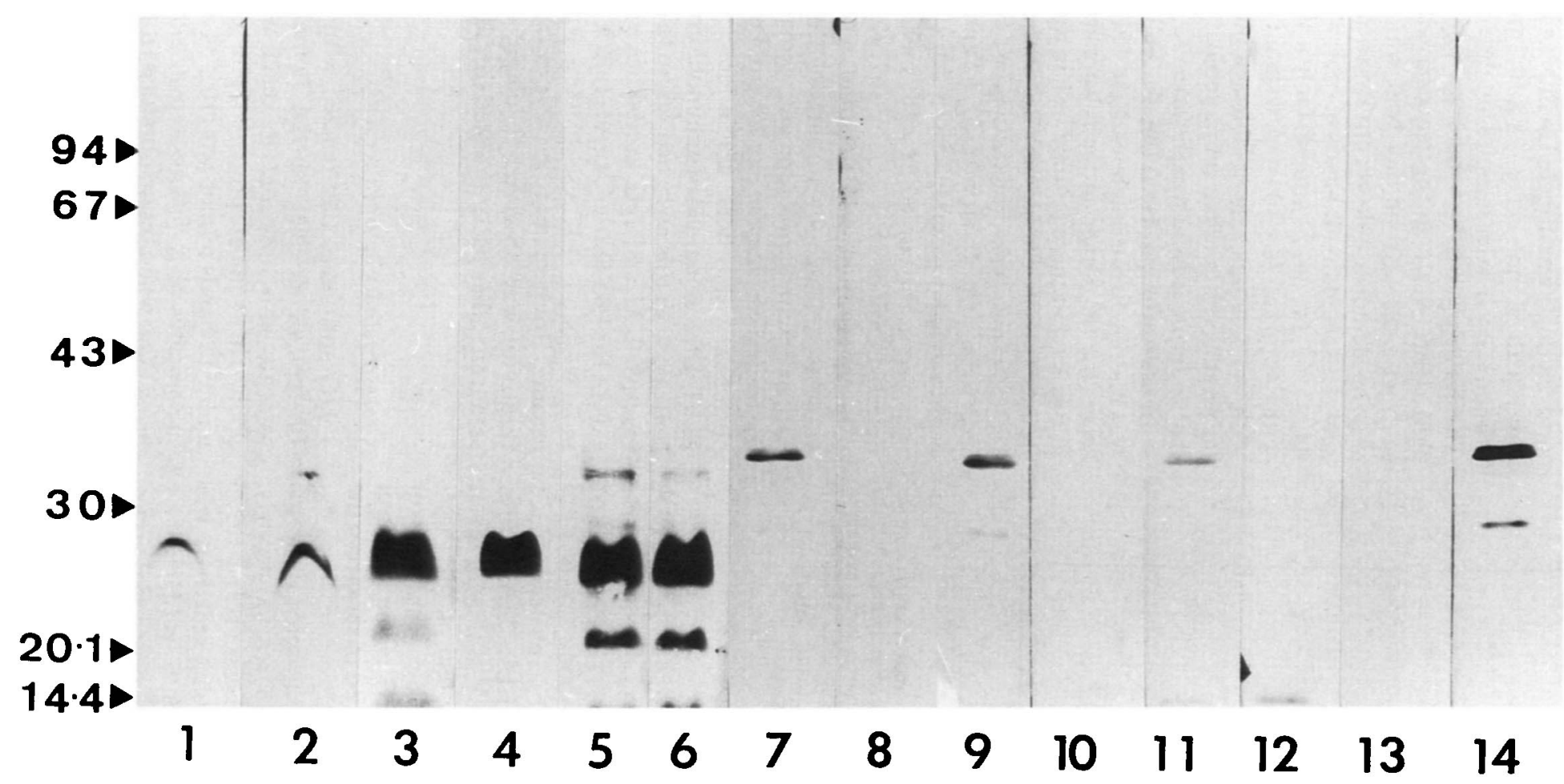

Fig. 3. Immunoblots of $L$. interrogans serovar hardjo sonicate (lanes 1 and 2), lipopolysaccharide (lanes 3-6) and flagella (lanes 7-14) with anti-LPS monoclonal antibodies and human sera. " $M$ " and " $G$ " denote the detection of human IgM and IgG antibodies respectively. Lanes 1 and 3 monoclonal antibody MUM/F1-1; lanes 2 and 4 monoclonal antibody MUM/F1-4; lanes 5 and 6, patient B serum; lanes 7 and 8, patient A serum; lanes 9 and 10, patient B serum; lanes 11 and 12 , patient $C$ serum; lanes 13 and 14, patient D serum. Numbers on the left indicate mol. wts $\left(10^{3}\right)$ of the standard proteins used. 

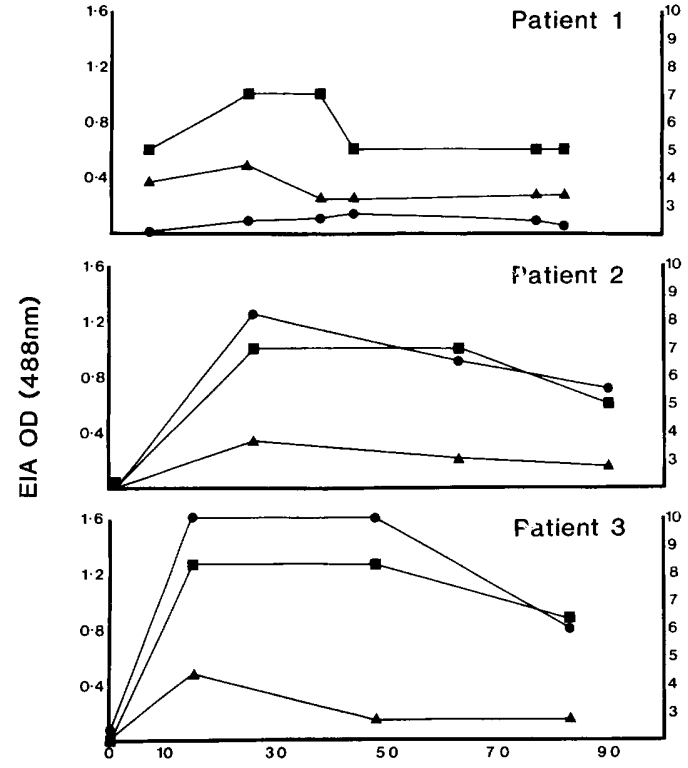

Time (days after positive culture)

Fig. 4. Time course of appearance of antibodies against $L$. interrogans serovar hardjo (L171) produced by patients $1-3$, as measured by MAT and EIA. Serum samples were numbered according to the number of days after a positive blood culture was obtained. EIA optical densities were subtracted for background. MAT: ; EIA IgM:

EIA IgG: $\longrightarrow$.

proved by blood culture, were tested by MAT, EIA and immunoblotting. Fig. 4 shows the time-course of antibody appearance in patients $1-3$ as measured by MAT and EIA. Peak antibody levels were recorded within 15-30 days of a positive blood culture, by both MAT and EIA. MAT titres gradually declined after the peak, although levels were still relatively high at the end of the threemonth sampling period. The peak concentration of IgM was higher than that of IgG in the serum of patient 1 but this was not observed in sera from the other two patients.

In immunoblotting tests with serovar hardjo sonicate, sera from patient 1 (fig. 5) reacted strongly, by IgM, with three bands of mol. wts $\left(10^{3}\right) c .15,23$ and 28 from day 7 onwards. Weak reactivity was also observed with a doublet of mol. wt (34-5-35) $\times$ $10^{3}$. The major band detected by IgG was the $28 \times$ $10^{3}$-mol. wt band observed to react with IgM antibodies; weak reactions with other bands of mol. wts $\left(10^{3}\right)$ c. $15,30,34 \cdot 5,35,44$ and 62 were also observed. Similar results were also obtained from sera collected on days 25, 38, 44 and 77 (results not shown). Sera from patient 2 (fig. 5) differed in their specific immunoglobulin content; only a small IgM response was observed, and this did not appear until day 26. It was directed mainly against a curved band with a mol. wt c. $28 \times 10^{3}$ and decreased dramatically in later samples but did not disappear. The IgG response was much greater than that of $\operatorname{IgM}$; there was a strong reaction with a band of mol. wt c. $52 \times 10^{3}$ on day 1 , at which time there was no demonstrable reactivity with $\operatorname{IgM}$. Later samples reacted with bands of mol. wts $\left(10^{3}\right) c .36$, $44,47,52,60,64,72$ and 95 . Only a slight reaction with the curved $28 \times 10^{3}-\mathrm{mol}$. wt band was observed with these samples. Sera collected on days 63 and 90 produced a similar immunoblot profile to the day 26 serum (results not shown).

In sera from patient 3 (fig. 5) the IgM response was mainly directed against a curved band of mol. wt c. $28 \times 10^{3}$. Other antigens were also recognised at day 15 , but these antibodies had disappeared by day 48 (results not shown). In contrast, a strong, $\mathrm{IgG}$ response was directed against bands of mol. wts $\left(10^{3}\right)$ c. $22,32,34 \cdot 5,35,52,62$ and 95 as well as a diffuse band of mol. wt $(15-20) \times 10^{3}$. No IgG response to the curved $28 \times 10^{3}-\mathrm{mol}$. wt band was detected until day 83 .

In an attempt to determine whether all the antigens detected by immunoblotting sera from patient 2, with hardjo sonicate, were present on the leptospiral surface, the day 26 serum was repeatedly absorbed with whole, viable leptospires until no MAT titre remained. Immunoblotting of hardjo sonicate with this absorbed serum revealed that all reactive $\operatorname{IgM}$ and $\mathrm{IgG}$ antibodies were removed, except for IgG antibodies reacting with a $52 \times 10^{3}-$ mol. wt band that also reacted with the day 1 sample from patient 2. A similar removal of reactivity was observed following absorption of sera from other patients tested (results not shown).

\section{Cross-reactivity between serovars}

IgG antibodies that reacted with a (34.5-35) $\times$ $10^{3}$-mol.wt doublet in the homologous hardjo sonicate also appeared to react with a similar doublet in a sonicate prepared from serovar pomona, and with bands of mol. wts $\left(10^{3}\right) 34$ and 35 present in sonicates of L. biflexa serovar patoc and Leptonema illini, when serum obtained from patient 3 on day 48 was immunoblotted with homologous and heterologous sonicates (fig. 6). A reaction was also observed with a band of mol. wt $c .42 \times 10^{3}$ and a diffuse band of mol. wt $(14.4-23) \times 10^{3}$ that were present only in serovars pomona and hardjo. Use of a hardjo flagella preparation indicated that the 


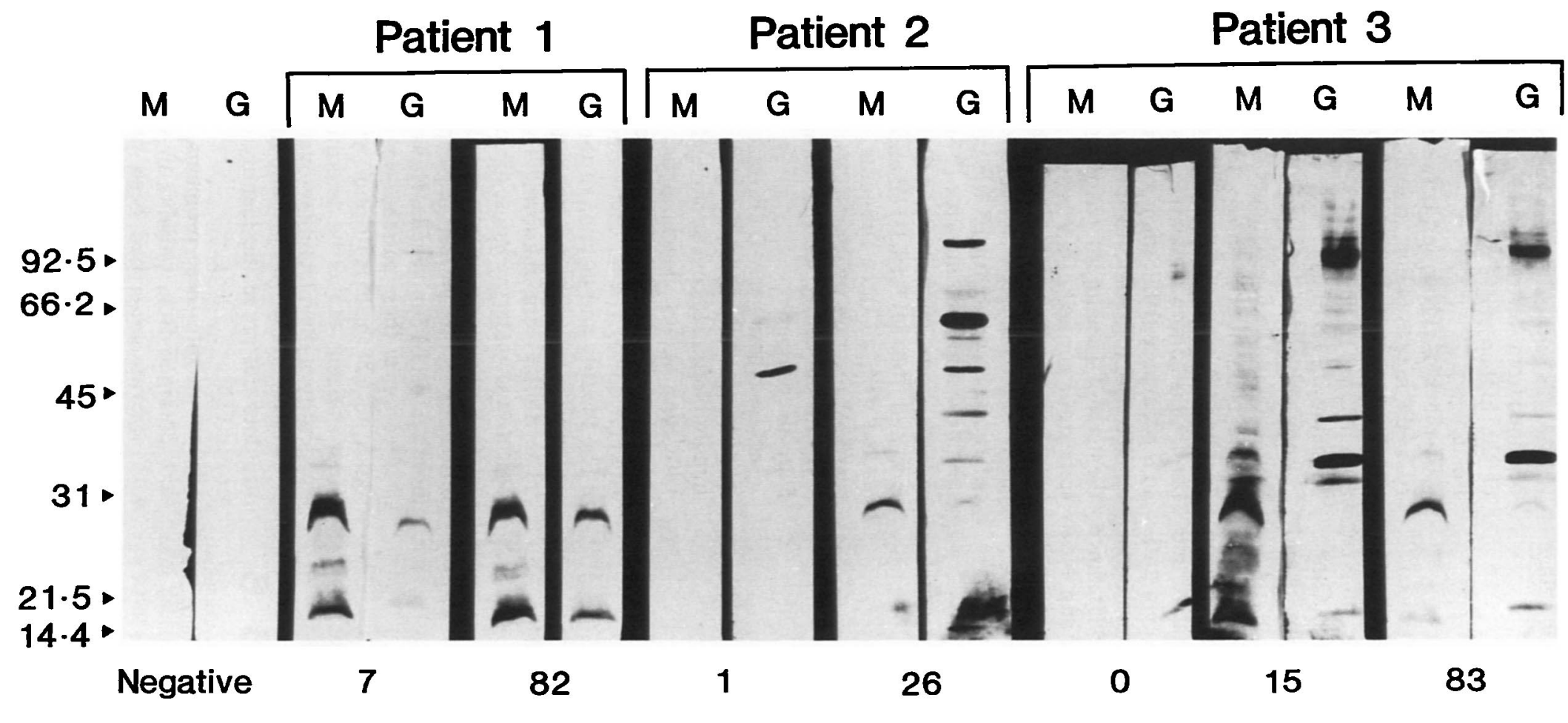

Days after positive culture

Fig. 5. Representative immunoblots of $L$. interrogans serovar hardjo sonicate with sequential serum samples from patients 1,2 and 3 . "M" and " $G$ " denote the detection of IgM and IgG antibodies respectively. "Neg." denotes lanes immunostained with human serum negative by EIA and MAT as a control. Serum samples were numbered according to the number of days after a positive blood culture was obtained. Numbers on the left indicate the mol. wts $\left(10^{3}\right)$ of the standard proteins used. 
$(34 \cdot 5-35) \times 10^{3}$ cross-reactive doublet was a flagellar component.

\section{Discussion}

SDS-PAGE protein profiles of three strains of $L$. interrogans serovar hardjo revealed minor differences between the isolates from Australia and New Zealand, and the type strain Hardjoprajitno. Others have found that hardjo isolates from Australia and New Zealand were indistinguishable by DNA restriction endonuclease analysis, but were markedly different from strain Hardjoprajitno (Robinson et al., 1982), and that there were qualitative and quantitative differences between the protein antigens of recently isolated hardjo strains and those of Hardjoprajitno (Nunes-Edwards et al., 1985). Since hardjo isolates obtained from Australia and New Zealand were very similar, the New Zealand strain

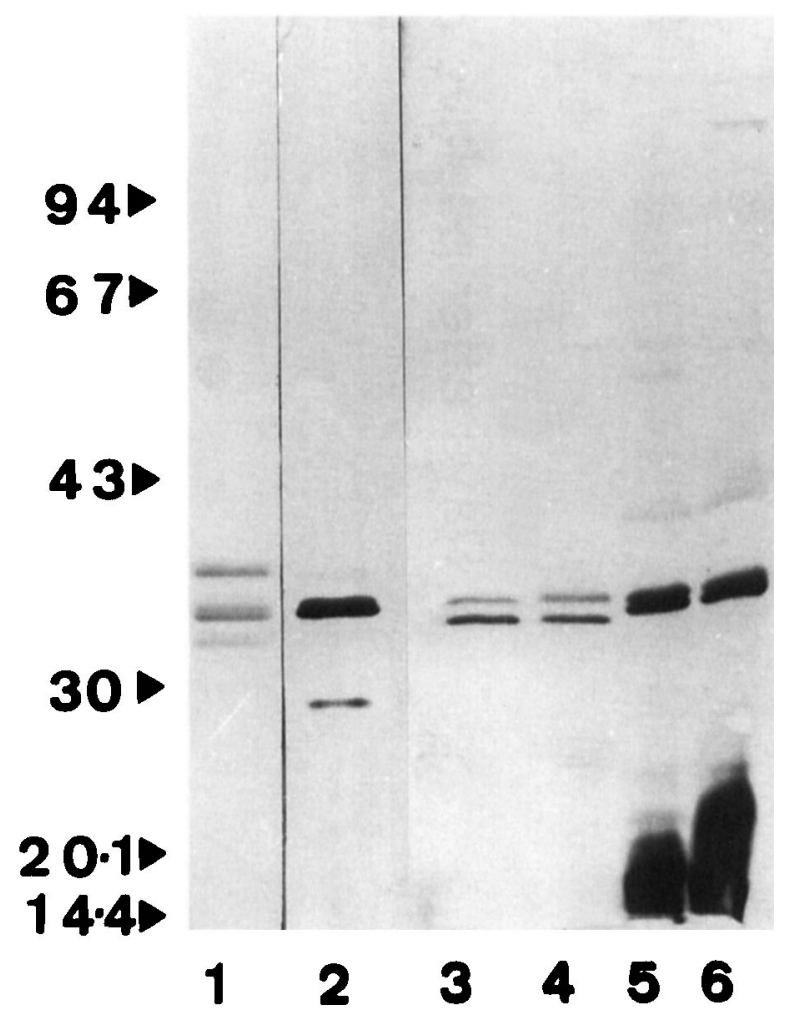

Fig. 6. SDS-PAGE of hardjo flagella stained with Coomassie blue (lane 1), and immunoblots of hardjo flagella (lane 2) and leptospiral sonicates (lanes 3-6) with serum obtained from patient 3 on day 48 . IgG antibodies detected only. Lanes 1 and $2, L$. interrogans serovar hardjo flagella preparation; lane $3, L$. illini sonicate; lane 4, L. biflexa serovar patoc sonicate; lane $5, L$. interrogans serovar pomona sonicate; lane $6, L$. interrogans serovar hardjo sonicate. Numbers on the left indicate the mol. wts $\left(10^{3}\right)$ of the standard proteins used.
(L171) was selected for use in testing human sera obtained from Australia and New Zealand, because of the higher cell density obtainable from this isolate.

The lack of correlation between MAT titre and EIA OD, in tests of human sera for the presence of leptospiral antibodies, confirms previous observations (Adler et al., 1980; Terpstra et al., 1980; Milner et al., 1985).

Immunoblotting revealed that $\operatorname{IgM}$ antibodies from each of the five patients A-E reacted with a curved band of mol. wt $28 \times 10^{3}$. Some sera also contained IgG antibodies that reacted with this band. This band was identified as a component of LPS because anti-LPS monoclonal antibodies also reacted with it in sonicated preparations, although the shape of the band differed depending on whether sonicate or purified LPS was used as the antigen.

Immunoblotting purified hardjo LPS with antihardjo LPS monoclonal antibodies and serum from patient B showed that LPS was composed of three sub-units, and that the $28 \times 10^{3}$-mol. wt sub-unit was the major component. Although the human sera and the MUM/F1-1 monoclonal antibody reacted with all three sub-units, MUM/F1-4 appeared to react only with the $28 \times 10^{3}$-mol. wt subunit, thus indicating that LPS components may not share all epitopes.

Sera from patients A-D also reacted with a (34.5$35) \times 10^{3}$-mol. wt doublet which was shown by immunoblotting to consist of flagellar components. Antibodies against flagella (axial filaments) have been demonstrated previously in sera from patients with leptospirosis (Adler and Faine, 1979).

The identity and location of the antigen associated with the $65 \times 10^{3}-\mathrm{mol}$. wt band which reacted only with IgG are unknown. The reaction may indicate a secondary response to a previous subclinical or undiagnosed infection; alternatively, the antibodies to this antigen may appear later than those against LPS or flagella. However, as the stage of infection in these patients was not known, the significance of the $65 \times 10^{3}$-mol. wt band and other minor antigens cannot be determined. Moreover, the identity of the infecting serovar was not proven by culture in these patients, and the highest MAT titre does not prove the identity of the infecting serovar (Turner, 1968).

To investigate these problems, serum samples were obtained from patients in whom infection with serovar hardjo had been proven by blood culture, a procedure that is usually successful only within the first week of illness (Turner, 1968). Although there was little correlation between MAT titre and EIA OD for individual serum samples, 
the times of appearance of antibodies as measured by MAT and EIA were similar and exhibited similar profiles during the course of infection. Differences observed between the $\operatorname{IgM}$ and $\mathrm{IgG}$ EIA profiles (fig. 4) may indicate a secondary response in the two patients in whom the IgM and IgG peaks occurred simultaneously. The finding that specific IgM levels detected by EIA declined after a strong initial response while specific IgG levels remained high suggests that EIA for the detection of specific IgM may be useful in discriminating between current and previous infections.

Immunoblotting hardjo sonicate with sera from patients $1-3$ revealed that there was little change in the antigens detected after the second to third week of infection. However, all patients produced IgM antibodies that reacted with the $28 \times 10^{3}-\mathrm{mol}$. wt component of LPS, although reactions to other LPS components differed. It is possible that patients producing only IgM LPS-reactive antibodies were experiencing a primary infection, whereas those producing both IgM and IgG antibodies reacting with LPS may have had a previous infection with serovar hardjo. However, as past histories of these patients were not known, no firm conclusions can be drawn.

There was more variability in the $\operatorname{IgG}$ than in the IgM reactivities of these sera. The IgG response of patient 1 was directed almost exclusively against LPS, whereas IgG from patients 2 and 3 reacted with bands ranging in mol. wt $\left(10^{3}\right)$ from 22 to 95 . However, it is possible that this variable IgG response was due to previous leptospiral infections, because immunoblotting detected specific IgG antibodies in the first serum samples taken, but IgM antibodies were not detected until later in the infection.

Immunoblotting of absorbed serum obtained from one patient 26 days after the positive blood culture showed that antibodies are produced against several leptospiral antigens, other than LPS, which are apparently exposed on the surface of the organism.

\section{REFERENCES}

Adler B, Faine S 1978 The antibodies involved in the human immune response to leptospiral infection. Journal of Medical Microbiology 11 : 387-400.

Adler B, Faine S 1979 Antibodies against leptospiral axial filament in human anti-Leptospira sera. FEMS Microbiology Letters 5: 57-60.

Adler B, Faine S 1980 Epidemiology of human leptospirosis in Australia. Communicable Diseases Intelligence (Australian Department of Health) 80/21:2-5.
Human sera cross-react widely when tested by MAT (Alston and Broom, 1958; Adler and Faine, 1978). Sera react even more widely by EIA, which also detects sub-surface, non-agglutinating antigens, and may, therefore, be used as a genusspecific test (Terpstra et al., 1980). Such genusspecific antigen preparations have been used in the serodiagnosis of human leptospirosis (Chang et al., 1957; Cox, 1957; Cox et al., 1957; Palit and Gulasekharam, 1973). Results obtained by immunoblotting serum, collected on day 48 from patient 3 , with homologous and heterologous sonicates (fig. 6) are consistent with cross-reactivity patterns we have previously observed with hyperimmune rabbit antisera (Chapman et al., in press). As genusspecific tests have been found to be positive earlier than the MAT (Turner, 1968) and genus reactivity is due, at least in part, to flagellar components, the use of purified flagella may be useful in the early diagnosis of leptospirosis.

The observation that IgG antibodies in the serum obtained on day 26 from patient 2 also reacted with low-mol. wt material present only in the pathogenic serovars tested, may indicate that species-specific as well as genus-specific antigens were detected.

Our results show that LPS is a major antigen involved in the human antibody response to infection with $L$. interrogans serovar hardjo. The response to other antigens, including flagella, appears to be variable. As LPS elicits protective antibodies in mice (Faine et al., 1974; Adler and Faine, 198¿b; Farrelly et al., 1987; Jost et al., 1986) and lacks endotoxic activity (Vinh et al., 1986b), LPS components may be useful as immunising agents. Studies are currently being undertaken to determine the antigens involved in the immune response to infection with other leptospiral serovars.

This work was supported by a research grant from the National Health and Medical Research Council, Canberra, Australia. We thank T. Vinh for preparation of lipopolysaccharide, and $\mathbf{J}$. Kelson for the preparation of flagella.

Adler B, Faine S 1983a Species-specific and genus-specific antigens in Leptospira, revealed by monoclonal antibodies and enzyme-immunoassay. Zentralblatt für Bakteriologie Mikrobiologie und Hygiene I Abteilung Originale A 255: 317 322 .

Adler B, Faine S $1983 b$ A Pomona serogroup-specific, agglutinating antigen in Leptospira, identified by monoclonal antibodies. Pathology 15: 247-250.

Adler B, Murphy A M, Locarnini S A, Faine S 1980 Detection of specific anti-leptospiral immunoglobulin $\mathrm{M}$ and immunoglobulin $\mathrm{G}$ in human serum by solid phase enzyme-linked 
immunosorbent assay. Journal of Clinical Microbiology 11 : $452-457$.

Alston J M, Broom J C 1958 Leptospirosis in man and animals. E. and S. Livingstone Ltd. Edinburgh.

Auran N E, Johnson R C, Alexander A D 1975 Chemical composition and serological activity of leptospiral outer envelope. Proceedings of the National Symposium on Leptospirosis, Leptospira and other Spirochaeta, Bucharest, pp 277-286.

Batteiger B, Newhall W J, Jones R B 1982 The use of Tween 20 as a blocking agent in the immunological detection of proteins transferred to nitrocellulose membranes. Journal of Immunological Methods 55: 297-307.

Blackmore D K, Schollum L 1982 Risks of contracting leptospirosis on the dairy farm. New Zealand Medical Journal 95 : 649-652.

Bradford M M 1976 A rapid and sensitive method for the quantitation of microgram quantities of protein utilizing the principle of protein-dye binding. Analytical Biochemistry 72: $248-254$.

Chang A, Faine S 1970 Electron microscopic evidence for reactions of axial filaments of Leptospira with $\mathrm{IgM}$ and $\mathrm{IgG}$ antibodies. Bulletin of the World Health Organization 43: 571-577.

Chang R S, Smith D J W, McComb D E, Sharp C F, Tonge J I 1957 The use of erythrocyte sensitizing substance in the diagnosis of leptospirosis. II. The sensitized erythrocyte lysis test. American Journal of Tropical Medicine and Hygiene 6: 101-107.

Chapman A J, Adler B, Faine S Genus-specific antigens in Leptospira revealed by immunoblotting. Zentralblatt für Bakteriologie Mikrobiologie und Hygiene I Abteilung Originale $A$ in press.

Cox C D 1957 Standardization and stabilization of an extract from Leptospira biflexa and its use in the hemolytic test for leptospirosis. Journal of Infectious Diseases 101 : 203-209.

Cox C D, Alexander A D, Murphy L C 1957 Evaluation of the hemolytic test in the serodiagnosis of human leptospirosis. Journal of Infectious Diseases 101 : 210-218.

Faine S 1982 Guidelines for the control of leptospirosis. WHO Offset Publication No. 67. World Health Organization, Geneva.

Faine S, Adler B, Ruta G 1974 A mechanism of immunity to leptospirosis. Australian Journal of Experimental Biology and Medical Science 52: 301-310.

Faine S, Adler B, Christopher W, Valentine R 1984 Fatal congenital human leptospirosis. Zentralblatt für Bakteriologie Mikrobiologie und Hygiene I Abteilung Originale A 257: 548.

Farrelly H E, Adler B, Faine S 1987 Opsonic monoclonal antibodies against lipopolysaccharide antigens of Leptospira interrogans serovar hardjo. Journal of Medical Microbiology 23: $1-7$

Hancock K, Tsang V C W 1983 India ink staining of proteins on nitrocellulose paper. Analytical Biochemistry 133: 157162.

Hawkes R, Niday E, Gordon J 1982 A dot-immunobinding assay for monoclonal and other antibodies. Analytical Biochemistry 119: 142-147.

Johnson D A, Gautsch J W, Sportsman J R, Elder J H 1984 Improved technique utilizing analysis of proteins and nucleic acids transferred to nitrocellulose. Gene Analysis Techniques 1 : 3-8.

Johnson R C, Walby J, Henry R A, Auran N E 1973 Cultivation of parasitic leptospires: effect of pyruvate. Applied Microbiology 26: 118-119.

Jost B H, Adler B, Vinh T, Faine S 1986 A monoclonal antibody reacting with a determinant on leptospiral lipopolysaccharide protects guinea pigs against leptospirosis. Journal of Medical Microbiology 22: 269-275.

Kaufmann A F 1976 Epidemiologic trends of leptospirosis in the United States, 1965-1974. In: Johnson R C (ed.) The biology of parasitic spirochetes. Academic Press, London, pp 177-189.

Laemmli U K 1970 Cleavage of structural proteins during the assembly of the head of bacteriophage T4. Nature 227: 680685.

Mackintosh C G et al., 1980 Epidemiology of leptospirosis in dairy farm workers in the Manawatu. 1. A cross-sectional serological survey and associated occupational factors. New Zealand Veterinary Journal 28 : 245-250.

Milner A R, Jackson K B, Woodruff K, Smart I J 1985 Enzymelinked immunosorbent assay for determining specific immunoglobulin $\mathbf{M}$ in infections caused by Leptospira interrogans serovar hardjo. Journal of Clinical Microbiology 22: 539-542.

Nunes-Edwards P L, Thiermann A B, Bassford P J, Stamm L V 1985 Identification and characterization of the protein antigens of Leptospira interrogans serovar hardjo. Infection and Immunity 48 : 492-497.

Palit A, Gulasekharam J 1973 Genus-specific leptospiral antigen and its possible use in laboratory diagnosis. Journal of Clinical Pathology 26 : 7-16.

Robinson A J, Ramadass P, Lee A, Marshall R B 1982 Differentiation of subtypes within Leptospira interrogans serovars hardjo, balcanica and tarassovi, by bacterial restriction endonuclease DNA analysis (BRENDA). Journal of Medical Microbiology 15 : 331-338.

Swart K S, Wilks C R, Jackson K B, Hayman J A 1983 Human leptospirosis in Victoria. The Medical Journal of Australia 1: $460-463$.

Terpstra W J, Ligthart G S, Schoone G J 1980 Serodiagnosis of human leptospirosis by enzyme-linked-immunosorbentassay (ELISA). Zentralblatt für Bakteriologie Mikrobiologie und Hygiene I Abteilung Originale A 247: 400-405.

Towbin H, Staehelin T, Gordon J 1979 Electrophoretic transfer of proteins from polyacrylamide gels to nitrocellulose sheets: procedure and some applications. Proceedings of the National Academy of Sciences of the USA. 76: 4350-4354.

Turner L H 1968 Leptospirosis 2. Serology. Transactions of the Royal Society of Tropical Medicine and Hygiene 62: 880-899.

Vinh T, Adler B, Faine S 1986a Ultrastructure and chemical composition of lipopolysaccharide extracted from Leptospira interrogans serovar copenhageni. Journal of General Microbiology 132: 103-109.

Vihn T, Adler B, Faine S 1986b Glycolipoprotein cytotoxin from Leptospira interrogans serovar copenhageni. Journal of General Microbiology 132: 111-123.

Westphal O, Jann K 1965 Bacterial lipopolysaccharides. Extraction with phenol-water and further applications of the procedure. Methods in Carbohydrate Chemistry 5: 8391.

Wolff J W 1953 The clarification of pathogenic leptospires. Symposium on the leptospires. Medical Science publication no. 1, US Government printing office, Washington D.C. pp 174-185.

Zeigler J A, VanEseltine W P 1975 Isolation and chemical characterization of outer envelope of Leptospira pomona. Canadian Journal of Microbiology 21 : 1102-1112. 